\title{
In vivo quantification of the $\left[{ }^{11} \mathrm{C}\right] \mathrm{DASB}$ binding in the normal canine brain using positron emission tomography
}

Olivia Taylor ${ }^{1 *}{ }^{*}$, Nick Van Laeken ${ }^{2 \dagger}$, Filip De Vos ${ }^{2}$, Ingeborgh Polis ${ }^{3}$, Tim Bosmans ${ }^{3}$, Ingeborg Goethals ${ }^{4}$, Rik Achten ${ }^{5}$, Andre Dobbeleir ${ }^{1,4}$, Eva Vandermeulen ${ }^{1}$, Chris Baeken ${ }^{6}$, Jimmy Saunders ${ }^{1}$ and Kathelijne Peremans ${ }^{1}$

\begin{abstract}
Background: $\left[{ }^{11} \mathrm{C}\right]$-3-amino-4-(2-dimethylaminomethyl-phenylsulfanyl)-benzonitrile $\left(\left[{ }^{11} \mathrm{C}\right] \mathrm{DASB}\right)$ is currently the mostly used radiotracer for positron emission tomography (PET) quantitative studies of the serotonin transporter (SERT) in the human brain but has never been validated in dogs. The first objective was therefore to evaluate normal $\left[{ }^{11} \mathrm{C}\right] \mathrm{DASB}$ distribution in different brain regions of healthy dogs using PET. The second objective was to provide less invasive and more convenient alternative methods to the arterial sampling-based kinetic analysis.

Results: A dynamic acquisition of the brain was performed during 90 min. The PET images were coregistered with the magnetic resonance images taken prior to the study in order to manually drawn 20 regions of interest (ROIs). The highest radioactivity concentration of $\left[{ }^{11} \mathrm{C}\right] \mathrm{DASB}$ was observed in the hypothalamus, raphe nuclei and thalamus and lowest levels in the parietal cortex, occipital cortex and cerebellum.

The regional radioactivity in those 20 ROls was quantified using the multilinear reference tissue model 2 (MRTM2) and a semi-quantitative method. The values showed least variability between 40 and $60 \mathrm{~min}$ and this time interval was set as the optimal time interval for $\left[{ }^{11} \mathrm{C}\right] \mathrm{DASB}$ quantification in the canine brain. The correlation $\left(\mathrm{R}^{2}\right)$ between the MRTM2 and the semi-quantitative method using the data between 40 and 60 min was $99.3 \%$ (two-tailed p-value $<0.01$ ).
\end{abstract}

Conclusions: The reference tissue models and semi-quantitative method provide a more convenient alternative to invasive arterial sampling models in the evaluation of the SERT of the normal canine brain. The optimal time interval for static scanning is set at 40 to 60 min after tracer injection.

Keywords: Dogs, $\left[{ }^{11} \mathrm{C}\right] \mathrm{DASB}, \mathrm{Brain}, \mathrm{PET}$, Serotonin transporter, Multilinear reference tissue model 2

\section{Background}

In vivo imaging of the living brain can be performed with positron emission tomography (PET), based on the detection of two opposite $511 \mathrm{keV}$ gamma-rays that result from the annihilation of a positron and a negatron. The serotonergic system is one of the major neurotransmitter systems in the brain and is involved in a variety of neuropsychiatric disorders including anxiety disorders, schizophrenia, drug abuse, depression [1]

\footnotetext{
* Correspondence: olivia.taylor@ugent.be

${ }^{\dagger}$ Equal contributors

'Department of Medical Imaging and Small Animal Orthopedics, Faculty of Veterinary Medicine, Ghent University, Salisburylaan 133, 9820 Merelbeke, Belgium

Full list of author information is available at the end of the article
}

Alzheimer and Parkinson's diseases [2, 3]. Also in the dog, involvement of the serotonergic system in impulsive aggression, anxiety and compulsive disorders was demonstrated with single photon emission computed tomography [4-6]. Moreover, the serotonin enhancing drugs used to treat human disorders are used in canine behavior medicine [7-9].

As the primary molecular target of the selective serotonin reuptake inhibitors (SSRIs), the most common antidepressant drugs used in human medicine, the serotonin transporter (SERT) has been the focus of many studies in the past years. It is located on the presynaptic nerve endings of serotonergic neurons. It terminates neurotransmission by removing serotonin 
from the synaptic cleft (reuptake in the presynaptic neuron) and modulates thus the extracellular serotonin concentration [10].

Intensive research into development of suitable radiotracers to visualize and quantify this transporter with functional imaging modalities occurred in the past years in human (for review, [11]), but also in animal studies [12-15]. The $\left[{ }^{11} \mathrm{C}\right]-3$-amino-4-(2-dimethylaminomethylphenylsulfanyl)-benzonitrile $\left(\left[{ }^{11} \mathrm{C}\right] \mathrm{DASB}\right)$ is a recently developed highly selective radiotracer with a nanomolar affinity for the SERT for PET imaging [16]. Several studies in humans [17-21] showed that the regional distribution of the $\left[{ }^{11} \mathrm{C}\right] \mathrm{DASB}$ was concordant with the known densities of SERT in the brain [22]. It is currently the most widely used radiotracer for PET quantitative studies of the SERT in human brain [2]. Up to now, $\left[{ }^{11} \mathrm{C}\right] \mathrm{DASB}$ has been investigated in rodents [23], pigs [24], cats [12] and nonhuman primates [14], but never in dogs. As canine behavioral and human neuropsychiatric disorders, such as anxiety, aggressive and compulsive disorders, share many similarities [25], the dog represents a very interesting animal model for the investigation of human neuropsychiatric disorders. Furthermore, dogs represent a more practical and available alternative to other laboratory animals such as rodents or nonhuman primates. We already demonstrated in past studies that the investigation of the canine brain using radionuclides in general is feasible and that the results showed many similarities with human imaging studies [4-6, 15, 26-30].

The two parameters usually used to evaluate the $\left[{ }^{11} \mathrm{C}\right] \mathrm{DASB}$ regional distribution are the total distribution volume $\left(\mathrm{V}_{\mathrm{T}}\right)$, representing the volume of tissue in which the radioligand would have to distribute to reach a concentration equal to that in the plasma [18], and the binding potential of the nondisplaceable compartment $\left(\mathrm{BP}_{\mathrm{ND}}\right)$, referring to the ratio at equilibrium of the specifically bound radioligand to that of the nondisplaceable radioligand in tissue [31]. The $\mathrm{V}_{\mathrm{T}}$ values can be estimated using invasive kinetic methods, such as one-tissue compartment (1TC), two-tissue compartment (2TC) [32] and the linear graphical approach of Logan [33], requiring the placement of an arterial catheter. The $V_{T}$ values can then be used to calculate indirectly binding potential values of the nondisplaceable compartment $\left(\mathrm{BP}_{\mathrm{ND}}\right)$ with the following equation [31]:

$$
B P_{N D}=\frac{V_{T}-V_{N D}}{V_{N D}}=\frac{V_{T}}{V_{N D}}-1
$$

where $\mathrm{BP}_{\mathrm{ND}}=$ ratio at equilibrium of specifically bound (to receptor) radioligand to that of the nondisplaceable (free and non-specifically bound) radioligand in tissue; $\mathrm{V}_{\mathrm{T}}=$ distribution volume of distribution of the total radioligand uptake in tissue in relation to total plasma concentration; $\mathrm{V}_{\mathrm{ND}}=$ volume of distribution of the nondisplaceable radioligand concentration in relation to total plasma concentration [31]. Those $\mathrm{BP}_{\mathrm{ND}}$ values can also be estimated by reference tissue methods, eliminating the need of arterial samples [19, 34, 35].

To the authors' knowledge, this is the first study using PET imaging to evaluate SERT in the canine brain. The first objective was to evaluate regional distribution of the SERT in the normal canine brain with the tracer $\left[{ }^{11} \mathrm{C}\right] \mathrm{DASB}$. The second objective was to determine the equilibrium period (time interval during which regional tracer distribution is stable) in an attempt to use a semiquantitative method to simplify the determination of the regional radiotracer uptake by using data from a static scan performed in that time interval. Furthermore, to correlate the regional tracer distribution values obtained with this semi-quantitative method with the data determined using a reference tissue method obtained from a dynamic scan.

\section{Methods}

\section{Animals}

Three healthy laboratory beagles and two purpose-bred laboratory dogs (four males and one female, 4 to 8 years old, weighting 11-32 kg) from the veterinary faculty of Ghent were enrolled. This prospective study was approved and conducted in accordance with the guidelines of the Ethical Committee of Ghent University (EC approval 2013/133).

The dogs were fasted for at least twelve hours before the scan. A $22 \mathrm{G}$ venous catheter was placed in one of the cephalic veins. The anesthetic protocol was similar for both the magnetic resonance imaging (MRI) and positron emission tomography/computed tomography (PET/CT) scan. They were premedicated with dexmedetomidin (Dexdomitor ${ }^{\circ} 375 \mu \mathrm{g} / \mathrm{m}^{2}$ body surface area, IM). Anesthesia was induced with propofol (Propovet ${ }^{\circ}$ 2-3 $\mathrm{mg} / \mathrm{kg}$ depending on effect, IV) and, after endotracheal intubation, maintained with isoflurane (Isoflo ${ }^{\circ}$ $1,2-1,4 \%$ given to effect, administrated in $100 \%$ oxygen via a circle system). A $22 \mathrm{G}$ arterial catheter was placed in one of the dorsal pedal arteries for the arterial sampling. Two anesthesiologists performed monitoring during and after anesthesia until the animals were fully awake.

\section{Imaging protocol}

All five dogs underwent a MRI prior to the PET examination. Images were collected on a Siemens $3 \mathrm{~T}$ Magnetom Trio Tim system (Siemens Medical Systems, Erlangen, Germany) using a phased-array spine coil and a phased-array body matrix coil. Animals were anesthetized 
and placed head first in sternal recumbency in the scanner bore, with the front limbs extended caudally.

A structural scan was acquired using a T1-weighted 3D MPRAGE sequence with 176 sagittal slices. Following sequence parameters were used: $\mathrm{TR}=2250 \mathrm{~ms}$, $\mathrm{TE}=4.18 \mathrm{~ms}, \quad \mathrm{TI}=900 \mathrm{~ms}$, parallel acquisition method $=$ GRAPPA with acceleration factor $=2$, matrix size $=256 \times 256$, sagittal, FOV $=220 \mathrm{~mm}$, flip angle $=$ $8^{\circ}$, voxel size $=0.9 \times 0.86 \times 0.86 \mathrm{~mm}^{3}$.

The $\left[{ }^{11} \mathrm{C}\right] \mathrm{DASB}$ was synthetized by $\mathrm{N}$-methylation of the precursor $\mathrm{N}$-desmethyl-DASB with $\left[{ }^{11} \mathrm{C}\right]$ methyltriflate as previously described [36]. High chemical purities (>99\%) were obtained. The specific activity at the time of radiotracer injection was $43 \pm 34 \mathrm{GBq} / \mu \mathrm{mol}$.

Dogs were placed on the PET camera (Gemini PET/ CT, Philips, Eindhoven, The Nederlands) in sternal recumbency with the front limbs extended caudally. A CT scan was performed for attenuation correction. The $\left[{ }^{11} \mathrm{C}\right] \mathrm{DASB}$ was injected intravenously (mean activity \pm SD: $7,8 \pm 1,6 \mathrm{mCi}$ or $289 \pm 60 \mathrm{MBq}$ ) after and before a

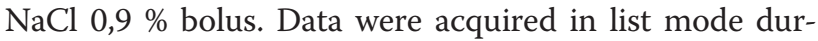
ing a 90 min dynamic acquisition of the brain. The acquisition was started simultaneously to the injection of the radiotracer. The list mode data were reconstructed in 901 -min frames for display purposes and determination of optimal scan time.

\section{Image analysis}

A PET summation image of all frames and dynamic images were manually coregistered to each individual MR images using PMOD software (PMOD Technologies, Zurich, Switzerland).
Regions of interest (ROIs) were selected based on the known distribution of the SERT and drawn based on an anatomical atlas [37]. Twenty ROIs were manually delineated in the raphe nuclei, hypothalamus, thalamus (left and right), hippocampus (left and right), cerebellum (left and right), frontal cortex (left and right), parietal cortex (left and right), temporal cortex (left and right), occipital cortex (left and right), basal ganglia (left and right), anterior cingulate gyrus and posterior cingulate gyrus (Fig. 1). Within the cerebral cortex, only gray matter was included into the ROIs to measure the PET activity distribution. The ROIs were delineated on the dorsal plane T1-weighted images and extended to the co-registered PET images. Regional radioactivity was determined for each frame, corrected for decay and plotted versus time.

The effect of the scanning time on parameter's stability was evaluated using the ratio analysis [18]. The ratios of five ROIs (raphe nuclei, thalamus, basal ganglia, frontal cortex and occipital cortex) over the cerebellum were determined for $20 \mathrm{~min}$-scans starting every $10 \mathrm{~min}$ from 0 up to $70 \mathrm{~min}$ from the dynamic acquisition. The standard error of the ratio for each time interval was calculated to evaluate the stability of the parameters and therefore the optimal scanning time.

Several methods have been described for the quantification of $\left[{ }^{11} \mathrm{C}\right] \mathrm{DASB}$ regional activity $[18,20,32,38]$. In this article, we measured the $\mathrm{BP}_{\mathrm{ND}}$ values using the multilinear reference tissue model 2 (MRTM2) and the cerebellum was chosen as the reference region, assuming the absence of SERT sites within this region [34]. As recommended by Meyer in his review paper [3], we selected the cerebellar cortex, excluding the vermis and keeping distance from white matter and venous sinuses. The

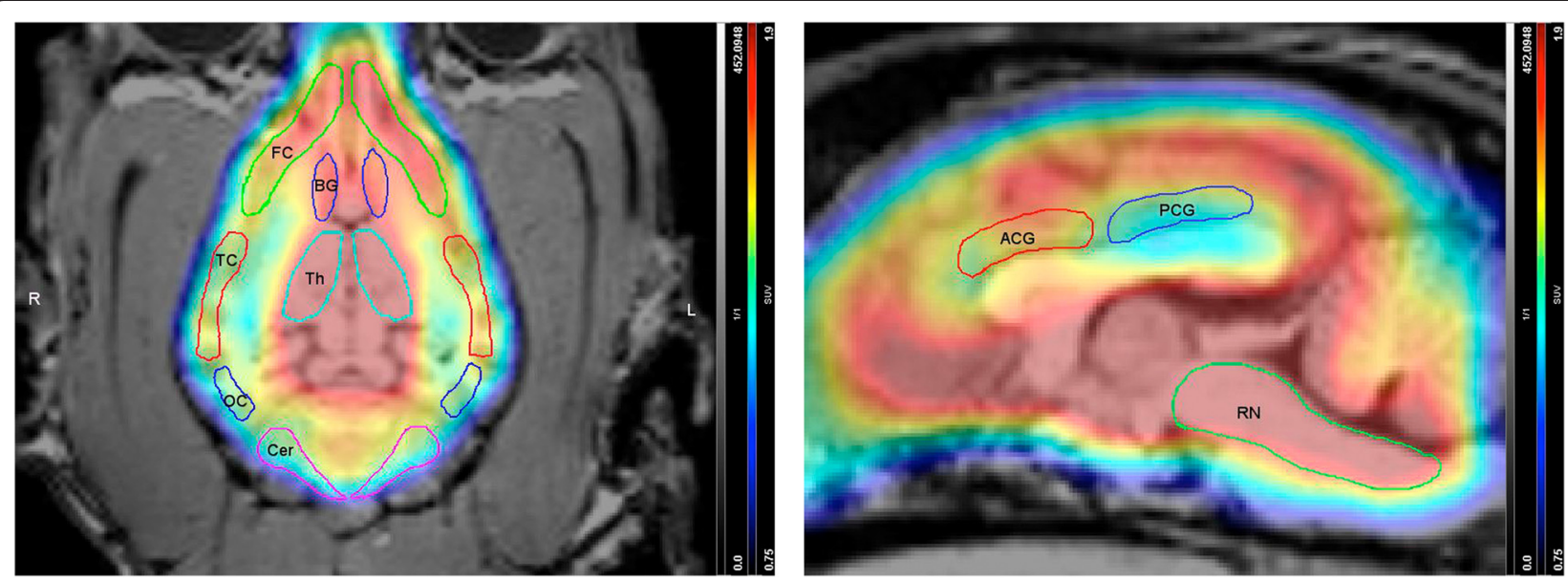

Fig. 1 Regions of interest representative of the $\left[{ }^{11} \mathrm{C}\right] \mathrm{DASB}$ distribution in the brain. Dorsal (left) and sagittal (right) sections of $\left[{ }^{11} \mathrm{C}\right] \mathrm{DASB}$ PET images fused with the corresponding MRI images. The following regions are displayed: frontal cortex (FC), temporal cortex (TC), occipital cortex $(\mathrm{OC})$, cerebellum (Cer), basal ganglia (BG), thalamus (Th), anterior cingulate cortex (ACG), posterior cingulate cortex (PCG) and the brainstem area where the raphe nuclei are located (RN) 
values were calculated using the PMOD software (PMOD Technologies, Zurich, Switzerland). The nomenclature used in this article is the consensus recommended by Innis and coworkers [31].

In addition to the aforementioned quantitative compartmental analysis (MRTM2), a semi-quantitative method was also evaluated using the ratio of the concentration of radioactivity within the ROIs at the optimal scanning time (determined based on the standard error values), over the concentration of radioactivity within the reference region (cerebellum). This simple quantification method is preferred in clinical surroundings as scan duration is considerably reduced and, similar to the reference tissue models, does not require arterial sampling. These values were then compared with those from the MRTM2.

\section{Statistical analysis}

To evaluate the usefulness of the semi-quantitative method, the coefficient of determination $\left(R^{2}\right)$ between $\left[{ }^{11} \mathrm{C}\right] \mathrm{DASB}$ binding potential values in 5 different regions (raphe nuclei, thalamus, basal ganglia, frontal cortex and occipital cortex) obtained from the MRTM2 and the values obtained from the semi-quantitative ratio analysis was calculated to estimate the correlation between those two methods. Statistical analysis was performed using SPSS software (version 18.0; SPSS, Chicago, IL).

\section{Results}

Regional time-activity curves

Regional time-activity curves (TACs) were obtained for each dog and each ROI. The highest radioactivity concentration of $\left[{ }^{11} \mathrm{C}\right] \mathrm{DASB}$ was observed in the hypothalamus, raphe nuclei and thalamus, intermediate levels were observed in the basal ganglia, hippocampus and frontal cortex, modest levels in the anterior and posterior cingulate gyri and temporal cortex, and low levels in the parietal cortex, occipital cortex and cerebellum. The TACs of six representative regions of different radioactivity levels, high (raphe nuclei and thalamus), intermediate (basal ganglia and frontal cortex) and low (occipital cortex and cerebellum), are displayed in Fig. 2.

\section{Optimal static scanning time}

Time curves of the ratios of radioactivity of five ROIs (raphe nuclei, thalamus, basal ganglia, frontal cortex and occipital cortex) over the cerebellum are displayed in Fig. 3. These curves demonstrate that the values reach a plateau after approximately $40 \mathrm{~min}$ and become more variable after approximately $60 \mathrm{~min}$ of scanning due to the decay of ${ }^{11} \mathrm{C}$.

The ratios of the same five ROIs representing regions of high (raphe nuclei and thalamus), moderate (basal ganglia and frontal cortex) and low (occipital cortex) SERT densities over the cerebellum were calculated for 20 min-scans starting every $10 \mathrm{~min}$ from the dynamic

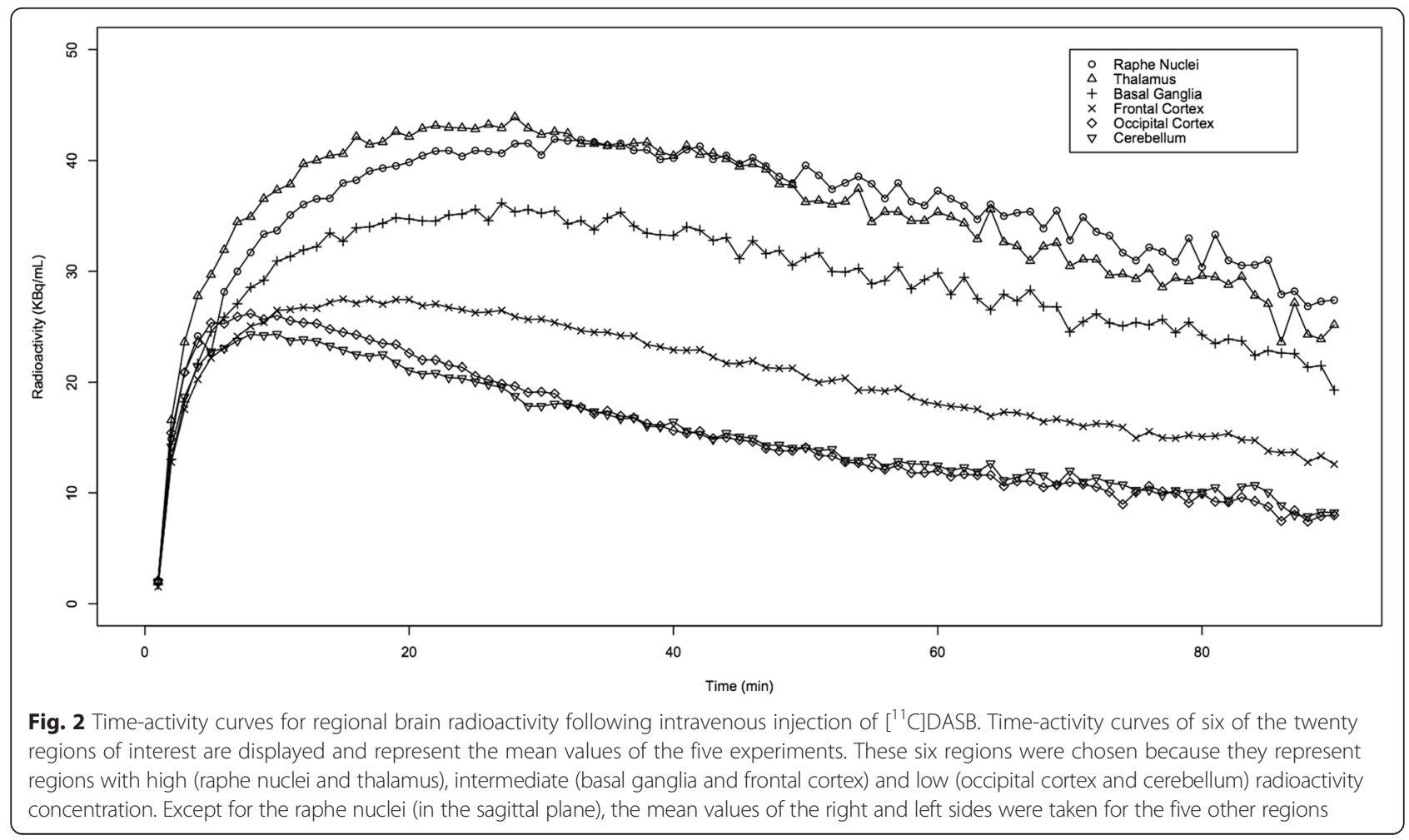




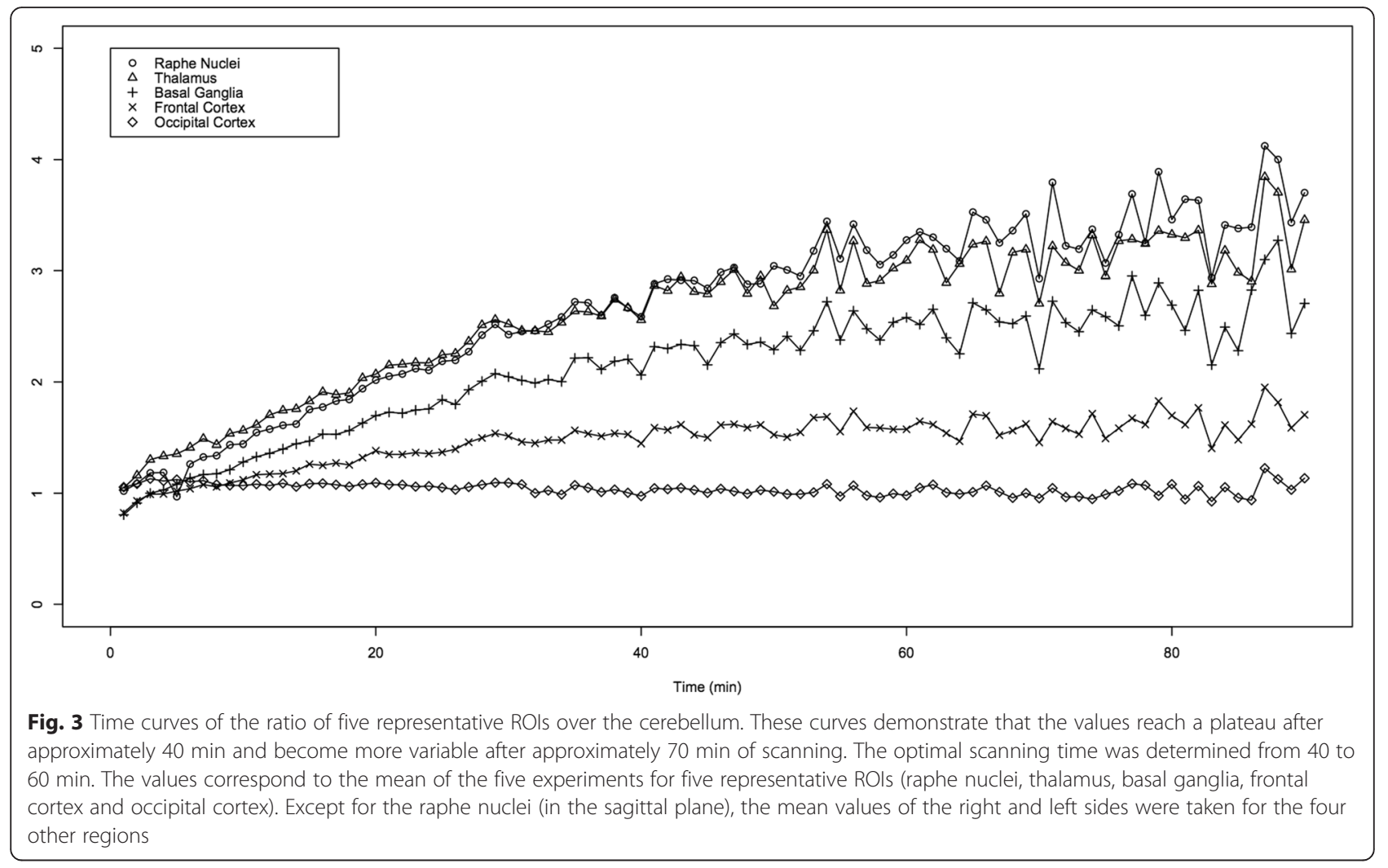

data. The standard error was determined in order to assess the stability of the parameters and the optimal scanning time (Table 1). The values were demonstrated to be less variable from 30 to $70 \mathrm{~min}$, the standard error values being $2.6 \%$ when scanning from 30 to $50 \mathrm{~min}$, $2.5 \%$ from 40 to $60 \mathrm{~min}$ and $2.9 \%$ from 50 to $70 \mathrm{~min}$. Therefore, the optimal scanning time was determined to be between 40 to $60 \mathrm{~min}$, as the standard error of the values obtained during this time interval was the lowest.

\section{Quantification of $\left[{ }^{11} \mathrm{C}\right] \mathrm{DASB}$ regional activity}

The $\mathrm{BP}_{\mathrm{ND}}$ values were derived from the reference tissue model MRTM2 using the cerebellum as a reference region (Table 2). These values were obtained for 18 ROIs (raphe nuclei, hypothalamus, left and right thalamus, left and right hippocampus, left and right frontal cortex, left and right parietal cortex, left and right temporal cortex, left and right occipital cortex, left and right basal ganglia, anterior cingulate gyrus, posterior cingulate gyrus),

Table 1 Ratio of five ROls over the cerebellum for 20 min-scans

\begin{tabular}{|c|c|c|c|c|c|c|}
\hline Scanning time (min) & Raphe nuclei & Thalamus & Basal ganglia & Frontal cortex & Occipital cortex & Mean SE \\
\hline 0 to 20 & $1,51 \pm 0,07$ & $1,64 \pm 0,06$ & $1,32 \pm 0,05$ & $1,15 \pm 0,03$ & $1,09 \pm 0,005$ & 0.045 \\
\hline 10 to 30 & $1,93 \pm 0,06$ & $2,02 \pm 0,06$ & $1,63 \pm 0,05$ & $1,31 \pm 0,02$ & $1,07 \pm 0,003$ & 0.042 \\
\hline 20 to 40 & $2,37 \pm 0,05$ & $2,40 \pm 0,04$ & $1,95 \pm 0,04$ & $1,45 \pm 0,02$ & $1,05 \pm 0,01$ & 0.031 \\
\hline 30 to 50 & $2,73 \pm 0,04$ & $2,69 \pm 0,04$ & $2,19 \pm 0,03$ & $1,53 \pm 0,01$ & $1,03 \pm 0,01$ & 0.026 \\
\hline 40 to 60 & $3,00 \pm 0,04$ & $2,89 \pm 0,03$ & $2,36 \pm 0,03$ & $1,57 \pm 0,01$ & $1,01 \pm 0,01$ & 0.025 \\
\hline 50 to 70 & $3,19 \pm 0,04$ & $2,99 \pm 0,04$ & $2,45 \pm 0,03$ & $1,57 \pm 0,02$ & $1,00 \pm 0,01$ & 0.029 \\
\hline 60 to 80 & $3,32 \pm 0,05$ & $3,10 \pm 0,04$ & $2,55 \pm 0,04$ & $1,59 \pm 0,02$ & $1,00 \pm 0,01$ & 0.034 \\
\hline 70 to 90 & $3,20 \pm 0,07$ & $3,03 \pm 0,05$ & $2,49 \pm 0,06$ & $1,58 \pm 0,03$ & $1,02 \pm 0,02$ & 0.046 \\
\hline
\end{tabular}

The values of the five ROls correspond to the mean values of the five experiments \pm standard error. Except for the raphe nuclei (in the sagittal plane), the mean values of the right and left sides were taken for the four other regions

The standard error (SE) was the lowest for the values between 40 and 60 min of scanning, which was therefore determined as the optimal time interval 
Table $2 \mathrm{BP}_{\mathrm{ND}}$ values obtained from MRTM2

\begin{tabular}{|c|c|}
\hline & MRTM2 \\
\hline Region & BPND \\
\hline Raphe nuclei & $1,80 \pm 0,37$ \\
\hline Hypothalamus & $1,75 \pm 0,34$ \\
\hline Hippocampus L & $0,93 \pm 0,43$ \\
\hline Hippocampus R & $0,85 \pm 0,18$ \\
\hline Thalamus L & $1,75 \pm 0,60$ \\
\hline Thalamus R & $1,70 \pm 0,40$ \\
\hline Frontal cortex R & $0,50 \pm 0,17$ \\
\hline Frontal cortex L & $0,50 \pm 0,23$ \\
\hline Basal ganglia $\mathrm{R}$ & $1,15 \pm 0,49$ \\
\hline Basal ganglia L & $1,27 \pm 0,77$ \\
\hline ACG & $0,39 \pm 0,26$ \\
\hline PCG & $0,25 \pm 0,17$ \\
\hline Temporal cortex $\mathrm{R}$ & $0,26 \pm 0,11$ \\
\hline Temporal cortex L & $0,28 \pm 0,19$ \\
\hline Occipital cortex R & $0,05 \pm 0,11$ \\
\hline Occipital cortex L & $0,05 \pm 0,10$ \\
\hline Parietal cortex $\mathrm{R}$ & $0,17 \pm 0,17$ \\
\hline Parietal cortex $\mathrm{L}$ & $0,20 \pm 0,18$ \\
\hline
\end{tabular}

The $\mathrm{BP}_{\mathrm{ND}}$ values for the MRTM2 method were automatically calculated using PMOD software and correspond to the mean \pm standard deviation of the five experiments for $18 \mathrm{ROIs}$ (raphe nuclei, hypothalamus, left and right thalamus, left and right hippocampus, left and right frontal cortex, left and right parietal cortex, left and right temporal cortex, left and right occipital cortex, left and right basal ganglia, anterior cingulate gyrus, posterior cingulate gyrus). The ROls over the left and right cerebellum were used as the reference region $B P$ binding potential of the nondisplaceable compartment, $L$ left, $R$ right

the last two ROIs over the left and right cerebellum being used as the reference region.

For the MRTM2, the $\mathrm{k}_{2}^{\prime}$ value was calculated using the Multilinear Reference Tissue Model (MRTM) as the mean $\mathrm{k}_{2}$ (clearance rate constant from a region of interest to plasma) value of five high-SERT binding regions: raphe nuclei, right and left thalamus, right and left basal ganglia. The mean value of the $k_{2}^{\prime}$ parameter for the five experiments was $0.096 \pm 0.013$.
Given the results of the aforementioned scanning time interval analysis, the semi-quantitative analysis was performed using the data between 40 to $60 \mathrm{~min}$. The ratios of the concentration of radioactivity within the same 18 ROIs over the cerebellum are presented in Table 3.

\section{Statistical analysis: comparison of methods}

The correlation $\left(R^{2}\right)$ between the values obtained from the reference tissue model MRTM2 and the semiquantitative ratio analysis using the data between 40 and 60 min was $99.3 \%$ (two-tailed p-value $<0.01$ ), and therefore statistically significant (Fig. 4).

\section{Discussion}

The primary objective of this study was to evaluate the SERT density in the normal canine brain from analysis of $\left[{ }^{11} \mathrm{C}\right]$ DASB regional distribution using PET imaging. The highest radioactivity levels were observed in the hypothalamus, raphe nuclei and thalamus, intermediate levels were observed in the basal ganglia, hippocampus and frontal cortex, modest levels in the anterior and posterior cingulate gyri and temporal cortex, and low levels in the parietal cortex, occipital cortex and cerebellum. These results are consistent with the previous human [17-21,39] and animal [12, 14] studies.

As previously mentioned, the two parameters $V_{T}$ and $\mathrm{BP}$ used to evaluate the $\left[{ }^{11} \mathrm{C}\right] \mathrm{DASB}$ regional distribution can be estimated using invasive and timeconsuming kinetic methods such as 1TC, 2TC and Logan graphical models which require the placement of an arterial catheter. BP values can also be estimated by reference tissue methods that represent a noninvasive alternative method to evaluate the SERT density of the canine brain, withdrawing the need of arterial samples. A previous study compared the $\mathrm{BP}_{\mathrm{ND}}$ values obtained via a $2 \mathrm{TC}$ model with those calculated using several reference tissue models, the simplified reference tissue model 2, the MRTM2 and the Logan noninvasive model. The MRTM2 model

Table 3 Semi-quantitative ratio analysis

\begin{tabular}{|c|c|c|c|c|c|}
\hline Region & Ratio & Region & Ratio & Region & Ratio \\
\hline Raphe nuclei & $3,03 \pm 0,51$ & Frontal cortex $\mathrm{R}$ & $1,59 \pm 0,25$ & Temporal cortex $\mathrm{R}$ & $1,25 \pm 0,20$ \\
\hline Hypothalamus & $2,85 \pm 0,55$ & Frontal cortex L & $1,57 \pm 0,29$ & Temporal cortex $\mathrm{L}$ & $1,27 \pm 0,31$ \\
\hline Hippocampus L & $2,07 \pm 0,44$ & Basal ganglia R & $2,13 \pm 0,74$ & Occipital cortex R & $1,32 \pm 0,52$ \\
\hline Hippocampus R & $2,05 \pm 0,30$ & Basal ganglia L & $2,22 \pm 0,94$ & Occipital cortex L & $1,29 \pm 0,45$ \\
\hline Thalamus L & $2,91 \pm 0,75$ & ACG & $1,41 \pm 0,38$ & Parietal cortex $\mathrm{R}$ & $1,17 \pm 0,21$ \\
\hline Thalamus R & $2,91 \pm 0,54$ & PCG & $1,22 \pm 0,24$ & Parietal cortex L & $1,21 \pm 0,23$ \\
\hline
\end{tabular}

Semi-quantitative values were obtained using the ratio analysis method: ratio of the concentration of radioactivity within the same 18 ROIs as for MRTM2 (Table 2 ) over the concentration of radioactivity within the cerebellum, using the data from 40 to $60 \mathrm{~min}$

The values correspond to the mean \pm standard deviation of the five experiments

Ratio ROI/cerebellum, $L$ left; $R$ right 


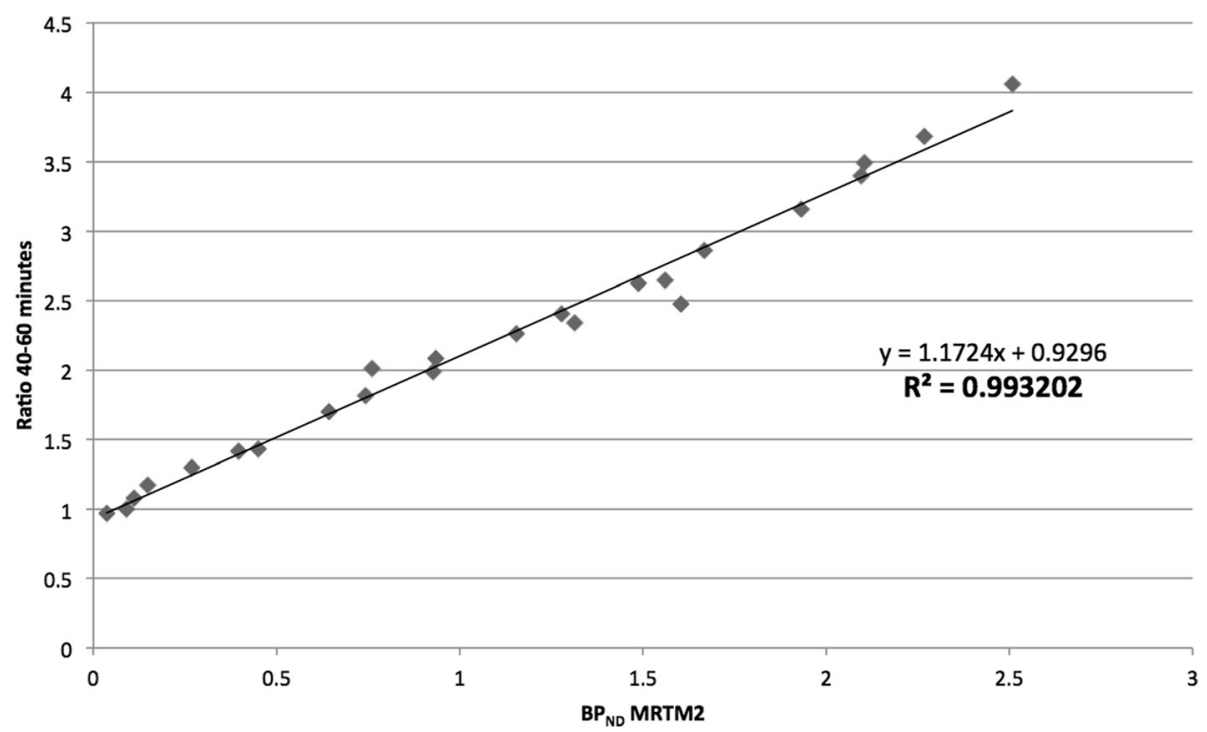

Fig. 4 Correlation between the semi-quantitative ratio analysis and the reference tissue model MRTM2. The coefficient of determination $\left(R^{2}\right)$ between the $\mathrm{BP}_{\mathrm{ND}}$ values obtained from the MRTM2 and the values obtained from the semi-quantitative analysis was determined. The values correspond to the five experiments for five ROls over representative regions of high (raphe nuclei and thalamus), intermediate (basal ganglia and frontal cortex) and low (occipital cortex) radioactivity concentration. Except for the raphe nuclei (in the sagittal plane), the mean values of the right and left sides were taken for the four other regions. $\mathrm{BP}_{\mathrm{ND}}=$ binding potential of the nondisplaceable compartment

demonstrated the highest correlation $\left(R^{2}=0.96\right)$ with the $2 \mathrm{TC}$, and was therefore chosen as reference tissue method of choice in our study [40].

To perform the reference tissue methods, the cerebellar cortex is selected as reference region. The properties required for an ideal reference region are similar free and nonspecific tracer binding properties as compared to regions with specific binding, and negligible specific binding of the radiotracer. Previously, the white matter and occipital cortex were also tested as reference regions. Although having very low levels of SERT, the possible difference of pharmacokinetics in free and nonspecific compartments between white matter and gray matter, caused the cerebellar cortex to become the more commonly used reference region, even though it is not completely devoid of SERT binding sites [41].

The second objective was to investigate the possibility of replacing the dynamic scan by a static acquisition. The influence of the scanning time was evaluated in order to assess whether it would be possible to perform a shorter $(20 \mathrm{~min})$ static acquisition instead of the 90 min dynamic acquisition for SERT binding estimations in patients. Our results demonstrated that the values show least variability between 40 and $60 \mathrm{~min}$. In human studies, ratios of radioactivity within the ROIs to that in the cerebellum were calculated using data from 55 to $90 \mathrm{~min}$ after injection of the radiotracer $[17,18]$. In our study, the ratio values were the most variable in the late acquisition, from 70 to $90 \mathrm{~min}(\mathrm{SE}=4.6 \%)$ despite relative higher injected activity compared to humans. The explanation could be the increase in noise towards the end of the scan because of the physical decay of the radionuclide $\left(\mathrm{T}_{1 / 2}\right.$ of $\left.{ }^{11} \mathrm{C}=20 \mathrm{~min}\right)$ [38]. For these reasons, it has been previously established in human studies that there is no need to scan longer than approximately 90 min [18, 20,38].

Finally, a semi-quantitative analysis was performed by measuring the ratio of the radioactivity within several ROIs to the radioactivity within the cerebellum, using the data from 40 to $60 \mathrm{~min}$. This method correlated significantly to the MRTM2 $\left(\mathrm{R}^{2}=0.993\right)$. Therefore, a $20 \mathrm{~min}$ static acquisition performed $40 \mathrm{~min}$ after intravenous injection of $\left[{ }^{11} \mathrm{C}\right] \mathrm{DASB}$ represents another more convenient and faster alternative method to evaluate the SERT of the canine brain in clinical surroundings.

The presence of $\left[{ }^{11} \mathrm{C}\right] \mathrm{DASB}$ radiometabolites in the brain and their potential interference with the measurements cannot be excluded. Nevertheless, $\left[{ }^{11} \mathrm{C}\right] \mathrm{DASB}$ is a highly selective radiotracer with a high affinity for the SERT [16]. Its radiometabolites are mainly polar and therefore unlikely to cross the blood-brain barrier and interfere with the measurements $[17,42]$.

\section{Conclusions}

Evaluation of the SERT in the canine brain can be performed after administration of $\left[{ }^{11} \mathrm{C}\right] \mathrm{DASB}$ using PET imaging. Given the similarities between canine behavioral disorders and human neuropsychiatric disorders, the dog could represent a valuable model for research about the involvement of the SERT in neuropsychiatry. 
Reference tissue methods based on a dynamic scan and the semi-quantitative ratio method based on a static scan provide less invasive and more convenient alternatives to the arterial sampling based kinetic analysis.

\begin{abstract}
Abbreviations
$\left[{ }^{11} \mathrm{C}\right] D A S B:\left[{ }^{11} \mathrm{C}\right]$-3-amino-4-(2-dimethylaminomethyl-phenylsulfanyl)benzonitrile; 1TC: one-tissue compartment; 2TC: two-tissue compartment; $\mathrm{BP}_{\mathrm{ND}}$ : binding potential of the nondisplaceable compartment; MRI: magnetic resonance imaging; MRTM2: multilinear reference tissue model 2; PET: positron emission tomography; PET/CT: positron emission tomography/ computed tomography; ROIs: regions of interest; SERT: serotonin transporter; SSRIs: selective serotonin reuptake inhibitors; TACs: time-activity curves; $V_{N D}$ : volume of distribution of the nondisplaceable compartment; $V_{T}$ : total distribution volume.
\end{abstract}

\section{Competing interests}

The authors declare that they have no competing interests.

\section{Authors' contributions}

OT and NVL supervised all experimental work, analyzed results, carried out the statistical analysis, and drafted the manuscript. NVL and FDV carried out the radiotracer synthesis and plasma metabolites analysis. TB and IP carried out the anesthesia. KP, AD, EV, FDV, IG, RA, CB and JS participated in the design and execution of the experiment, data analysis and helped to draft the manuscript. All authors read and approved the final manuscript.

\section{Acknowledgements}

\section{Sources of funding}

None.

\section{Author details}

'Department of Medical Imaging and Small Animal Orthopedics, Faculty of Veterinary Medicine, Ghent University, Salisburylaan 133, 9820 Merelbeke, Belgium. '2Laboratory of Radiopharmacy, Faculty of Pharmaceutical Sciences, Ghent University, Ottergemsesteenweg 460, 9000 Ghent, Belgium. ${ }^{3}$ Department of Medicine and Clinical Biology of Small Animals, Faculty of Veterinary Medicine, Ghent University, Salisburylaan 133, 9820 Merelbeke, Belgium. ${ }^{4}$ Department of Nuclear Medicine, Ghent University Hospital, Ghent University, De Pintelaan 185, 9000 Ghent, Belgium. ${ }^{5}$ Department of Radiology, Ghent University Hospital, Ghent University, De Pintelaan 185, 9000 Ghent, Belgium. ${ }^{6}$ Department of Psychiatry and Medical Psychology, Ghent University Hospital, Ghent University, De Pintelaan 185, 9000 Ghent, Belgium.

Received: 12 August 2015 Accepted: 18 December 2015

Published online: 24 December 2015

\section{References}

1. Meyer JH, Houle S, Sagrati S, Carella A, Hussey DF, Ginovart N, et al. Brain serotonin transporter binding potential measured with carbon 11-labeled DASB positron emission tomography: effects of major depressive episodes and severity of dysfunctional attitudes. Arch Gen Psychiatry. 2004;61(12):1271-9. doi:10.1001/archpsyc.61.12.1271

2. Hesse S, Barthel H, Schwarz J, Sabri O, Muller U. Advances in in vivo imaging of serotonergic neurons in neuropsychiatric disorders. Neurosci Biobehav Rev. 2004:28(6):547-63. doi:10.1016/j.neubiorev.2004.08.004.

3. Meyer JH. Imaging the serotonin transporter during major depressive disorder and antidepressant treatment. J Psychiatry Neurosci. 2007;32(2):86-102.

4. Peremans K, Audenaert K, Coopman F, Blanckaert P, Jacobs F, Otte A, et al. Estimates of regional cerebral blood flow and 5-HT2A receptor density in impulsive, aggressive dogs with 99mTc-ECD and 123I-5-I-R91150. Eur J Nucl Med Mol Imaging. 2003;30(11):1538-46. doi:10.1007/s00259-003-1250-X.

5. Vermeire ST, Audenaert KR, Dobbeleir AA, De Meester RH, De Vos FJ, Peremans KY. Evaluation of the brain 5-HT2A receptor binding index in dogs with anxiety disorders, measured with 123l-5I-R91150 and SPECT. J Nucl Med. 2009;50(2):284-9. doi:10.2967/jnumed.108.055731.

6. Vermeire $S$, Audenaert $K$, De Meester $R$, Vandermeulen $E$, Waelbers T, De Spiegeleer $B$, et al. Serotonin 2A receptor, serotonin transporter and dopamine transporter alterations in dogs with compulsive behaviour as a promising model for human obsessive-compulsive disorder. Psychiatry Res. 2012;201(1):78-87. doi:10.1016/j.pscychresns.2011.06.006.

7. Dodman NH, Donnelly R, Shuster L, Mertens P, Rand W, Miczek K. Use of fluoxetine to treat dominance aggression in dogs. J Am Vet Med Assoc. 1996:209(9):1585-7.

8. Overall KL, Dunham AE. Clinical features and outcome in dogs and cats with obsessive-compulsive disorder: 126 cases (1989-2000). J Am Vet Med Assoc. 2002;221(10):1445-52.

9. Wald R, Dodman N, Shuster L. The combined effects of memantine and fluoxetine on an animal model of obsessive compulsive disorder. Exp Clin Psychopharmacol. 2009;17(3):191-7. doi:10.1037/a0016402.

10. Horschitz S, Hummerich R, Schloss P. Structure, function and regulation of the 5-hydroxytryptamine (serotonin) transporter. Biochem Soc Trans. 2001:29(Pt 6):728-32.

11. Saulin A, Savli M, Lanzenberger R. Serotonin and molecular neuroimaging in humans using PET. Amino Acids. 2012;42(6):2039-57. doi:10.1007/s00726011-1078-9.

12. Ginovart N, Wilson AA, Meyer JH, Hussey D, Houle S. [11C]-DASB, a tool for in vivo measurement of SSRI-induced occupancy of the serotonin transporter: PET characterization and evaluation in cats. Synapse. 2003;47(2):123-33. doi:10.1002/syn.10155.

13. Stehouwer JS, Jarkas N, Zeng F, Voll RJ, Williams L, Camp VM, et al. Synthesis, radiosynthesis, and biological evaluation of fluorine-18-labeled 2beta-carbo(fluoroalkoxy)-3beta-(3'-((Z)-2-haloethenyl)phenyl)nortropanes: candidate radioligands for in vivo imaging of the serotonin transporter with positron emission tomography. J Med Chem. 2008;51(24):7788-99. doi:10. 1021/jm800781a.

14. Yokoyama C, Yamanaka H, Onoe K, Kawasaki A, Nagata H, Shirakami K, et al. Mapping of serotonin transporters by positron emission tomography with [11C]DASB in conscious common marmosets: comparison with rhesus monkeys. Synapse. 2010;64(8):594-601. doi:10. 1002/syn.20766

15. Peremans K, Goethals I, De Vos F, Dobbeleir A, Ham H, Van Bree H, et al. Serotonin transporter and dopamine transporter imaging in the canine brain. Nucl Med Biol. 2006:33(7):907-13. doi:10.1016/j.nucmedbio.2006.07.013.

16. Wilson AA, Ginovart N, Schmidt M, Meyer JH, Threlkeld PG, Houle S. Novel radiotracers for imaging the serotonin transporter by positron emission tomography: synthesis, radiosynthesis, and in vitro and ex vivo evaluation of (11)C-labeled 2-(phenylthio)araalkylamines. J Med Chem. 2000;43(16):3103-10.

17. Houle S, Ginovart N, Hussey D, Meyer JH, Wilson AA. Imaging the serotonin transporter with positron emission tomography: initial human studies with [11C]DAPP and [11C]DASB. Eur J Nucl Med. 2000;27(11):1719-22.

18. Ginovart N, Wilson AA, Meyer JH, Hussey D, Houle S. Positron emission tomography quantification of [(11)C]-DASB binding to the human serotonin transporter: modeling strategies. J Cereb Blood Flow Metab. 2001;21(11): 1342-53. doi:10.1097/00004647-200111000-00010.

19. Ichise M, Liow JS, Lu JQ, Takano A, Model K, Toyama H, et al. Linearized reference tissue parametric imaging methods: application to [11C]DASB positron emission tomography studies of the serotonin transporter in human brain. J Cereb Blood Flow Metab. 2003;23(9):1096-112. doi:10.1097/ 01.WCB.0000085441.37552.CA.

20. Frankle WG, Slifstein M, Gunn RN, Huang Y, Hwang DR, Darr EA, et al. Estimation of serotonin transporter parameters with 11C-DASB in healthy humans: reproducibility and comparison of methods. J Nucl Med. 2006;47(5):815-26.

21. Turkheimer FE, Selvaraj S, Hinz R, Murthy V, Bhagwagar Z, Grasby P, et al, Quantification of ligand PET studies using a reference region with a displaceable fraction: application to occupancy studies with [(11)C]-DASB as an example. J Cereb Blood Flow Metab. 2012;32(1):70-80. doi:10.1038/jcbfm. 2011.108.

22. Laruelle M, Vanisberg MA, Maloteaux JM. Regional and subcellular localization in human brain of [3H]paroxetine binding, a marker of serotonin uptake sites. Biol Psychiatry. 1988;24(3):299-309.

23. Wilson AA, Ginovart N, Hussey D, Meyer J, Houle S. In vitro and in vivo characterisation of [11C]-DASB: a probe for in vivo measurements of the serotonin transporter by positron emission tomography. Nucl Med Biol. 2002:29(5):509-15.

24. Jensen SB, Smith DF, Bender D, Jakobsen S, Peters D, Nielsen EO, et al. [11C]-NS 4194 versus [11C]-DASB for PET imaging of serotonin transporters in living porcine brain. Synapse. 2003:49(3):170-7. doi:10.1002/syn.10222. 
25. Overall KL. Natural animal models of human psychiatric conditions: assessment of mechanism and validity. Prog Neuropsychopharmacol Biol Psychiatry. 2000;24(5):727-76.

26. Peremans $\mathrm{K}$, Audenaert $\mathrm{K}$, Blanckaert $\mathrm{P}$, Jacobs $\mathrm{F}$, Coopman F, Verschooten $\mathrm{F}$, et al. Effects of aging on brain perfusion and serotonin-2A receptor binding in the normal canine brain measured with single photon emission tomography. Prog Neuropsychopharmacol Biol Psychiatry. 2002;26(7-8):1393-404.

27. Peremans K, Audenaert K, Jacobs F, Dumont F, De Vos F, Van De Wiele C, et al. Biodistribution and displacement studies of the selective 5-HT2A receptor antagonist 123I-5-I-R91150 in the normal dog. Nucl Med Commun. 2002:23(10):1019-27.

28. Peremans K, Audenaert K, Coopman F, Jacobs F, Dumont F, Slegers G, et al. Regional binding index of the radiolabeled selective 5 -HT2A antagonist 123I-5-I-R91150 in the normal canine brain imaged with single photon emission computed tomography. Vet Radiol Ultrasound. 2003;44(3):344-51.

29. Vermeire SAK, Dobbeleir A, De Meester R, Vandermeulen E, Waelbers T, Peremans K. Regional cerebral blood flow changes in dogs with anxiety disorders, measured with SPECT. Brain Imaging Behav. 2009;3(4):342-9.

30. Vermeire $S$, Audenaert $K$, De Meester R, Vandermeulen E, Waelbers T, De Spiegeleer B, et al. Neuro-imaging the serotonin $2 \mathrm{~A}$ receptor as a valid biomarker for canine behavioural disorders. Res Vet Sci. 2011;91(3):465-72. doi:10.1016/.rvsc.2010.09.021.

31. Innis RB, Cunningham VJ, Delforge J, Fujita M, Gjedde A, Gunn RN, et al. Consensus nomenclature for in vivo imaging of reversibly binding radioligands. J Cereb Blood Flow Metab. 2007;27(9):1533-9. doi:10.1038/sj. jcbfm.9600493.

32. Watabe H, lkoma Y, Kimura Y, Naganawa M, Shidahara M. PET kinetic analysis-compartmental model. Ann Nucl Med. 2006;20(9):583-8.

33. Logan J, Fowler JS, Volkow ND, Wolf AP, Dewey SL, Schlyer DJ, et al. Graphical analysis of reversible radioligand binding from time-activity measurements applied to [N-11C-methyl]-(-)-cocaine PET studies in human subjects. J Cereb Blood Flow Metab. 1990;10(5):740-7. doi:10.1038/jcbfm. 1990.127.

34. Lammertsma AA, Hume SP. Simplified reference tissue model for PET receptor studies. Neuroimage. 1996;4(3 Pt 1):153-8. doi:10.1006/nimg.1996. 0066.

35. Logan J, Fowler JS, Volkow ND, Wang GJ, Ding YS, Alexoff DL. Distribution volume ratios without blood sampling from graphical analysis of PET data. J Cereb Blood Flow Metab. 1996;16(5):834-40. doi:10.1097/00004647199609000-00008.

36. Van Laeken N, Kersemans K, De Meestere D, Goethals I, De Vos F. Improved HPLC purification strategy for [11C]raclopride and [11C]DASB leading to high radiochemical yields and more practical high quality radiopharmaceutical formulations. Appl Radiat Isot. 2013;78:62-7. doi:10.1016/j.apradiso.2013.04.009.

37. Lim RKS, Liu CLL, Moffitt RL. A stereotaxic atlas of the dog's brain Springfield: Charles C. Thomas; 1960.

38. Ogden RT, Ojha A, Erlandsson K, Oquendo MA, Mann JJ, Parsey RV. In vivo quantification of serotonin transporters using [(11)C]DASB and positron emission tomography in humans: modeling considerations. J Cereb Blood Flow Metab. 2007;27(1):205-17. doi:10.1038/sj.jcbfm.9600329.

39. Takano H, Ito H, Takahashi H, Arakawa R, Okumura M, Kodaka F, et al. Serotonergic Neurotransmission in the Living Human Brain: A Positron Emission Tomography Study Using [C-11]DASB and [C-11]WAY100635 in Young Healthy Men. Synapse. 2011;65(7):624-33. doi:10.1002/syn.20883.

40. Van Laeken N, Taylor O, Dobbeleir A, Polis I, Vandermeulen E, Bosmans T, et al. Evaluation of the PET-radioligand [11C]DASB in dogs. Seoul: World Molecular Imaging Congress; 2014.

41. Kish SJ, Furukawa Y, Chang $\sqcup$, Tong J, Ginovart N, Wilson A, et al. Regiona distribution of serotonin transporter protein in postmortem human brain: is the cerebellum a SERT-free brain region? Nucl Med Biol. 2005;32(2):123-8. doi:10.1016/..nucmedbio.2004.10.001.

42. Pike WW. PET radiotracers: crossing the blood-brain barrier and surviving metabolism. Trends Pharmacol Sci. 2009;30(8):431-40. doi:10.1016/j.tips.2009. 05.005.

\section{Submit your next manuscript to BioMed Central and we will help you at every step:}

- We accept pre-submission inquiries

- Our selector tool helps you to find the most relevant journal

- We provide round the clock customer support

- Convenient online submission

- Thorough peer review

- Inclusion in PubMed and all major indexing services

- Maximum visibility for your research

Submit your manuscript at www.biomedcentral.com/submit

) Biomed Central 